\title{
Determinants of long-term growth in India: a Keynesian approach
}

\section{Sushanta K. Mallick}

The Royal Institute of International Affairs, London, UK

\begin{abstract}
This paper attempts an eclectic synthesis on long-term growth, which integrates two standard models - the neoclassical model with the endogenous growth and export-led model of growth. A vector autoregressive (VAR) model has been used for India from 1950 to 1995 using Johansen's multivariate cointegration approach to derive latent equilibrium relationships, and the short-run error correction equations are then estimated. Two cointegrating relationships for real output and real private investment, respectively, were found. Output is determined by private investment, human capital, real interest rate and public investment. Private investment is driven by public investment, domestic credit to the private sector, real interest rate and human capital. This seems to support a McKinnon-Shaw model in the long run and a Keynesian/Structuralist view in the short run. The long-run model also validates the hypothesis that growth has not been export-led in India, rather it is growth-driven exports.
\end{abstract}

Key words: demand-driven growth, endogenous growth, export-led growth.

\section{Introduction}

Recently, there has been a growing concern with the theoretical and econometric analysis of growth-oriented adjustment in developing economies (DEs). The standard model of economic growth has been mostly supply-driven within the framework of neoclassical theory in which the process of capital accumulation is driven by household savings behaviour and in which aggregate demand effects are absent. In this paper we first survey the existing growth theories and then analyse factors determining real GDP growth on the demand side in the context of India. This has been warranted by a noted continued drop in capital formation (see Mallick and Kumar, 1995), which suggests that, of the components of GDP, investment has been (one of) the slowest growing. The reality of India's economic policy is that there has been a serious misallocation of resources by the public sector and the economy is showing clear symptoms of an 
impending fiscal crisis. The combined central and state government deficits currently exceed $10 \%$ of GDP, threatening a broader economic crisis. Despite continued efforts by the government to carry out pro-growth market-friendly reforms, vested interests by India's bureaucracy have emerged as a stumbling block, paralysing the decision making process. However, a better economic performance hinges crucially on freeing funds for badly needed investment in infrastructure and social development, and curtailing the government's huge expenditure (see Mallick, 2001). Accordingly, this paper models output and private investment on the assumption that declining levels of investment expenditure lead to a shortage of physical capital and thereby retard economic growth.

The core part of the analytical framework of the World Bank's gap models for funding DE structural adjustment (for an overview of the gap models see Bacha (1990) and Taylor (1994)) advocates that higher investment is necessary for long-term growth. In other words, this implies that it is the rate of growth of demand that may constrain the rate of output growth. In a growth context, Keynesian economics also emphasizes the primacy of investment spending by firms in determining capital accumulation and the rate of technical progress (Palley, 1996, 1997). The other strand of growth literature is based on export-led growth theories as to whether exports influence economic growth. Expansion of productive capacity through income growth can raise exports, and increased profitability of exports can induce increased saving and thereby capital emplacement, which gives rise to high economic growth. The controversy over the relation between export performance and economic growth has been a subject of continuous discussion in the literature. A number of studies have examined the theoretical and empirical aspects of the relations between exports and economic growth using cross-country statistical comparisons (for a detailed survey, see Mallick, 1995).

As the existing growth theories for model building are complex, it is important to examine the two different theories of growth within a unified framework. These conflicting views motivate us to reinvestigate factors determining India's economic growth, in particular whether growth can be described by incorporating the mechanisms of endogenous growth with export-led growth or/and growth theory in a Keynesian mode (see Palley, 1996). The latter requires the mechanisms of endogenous growth with capital accumulation being governed by investment spending (rather than saving). Thus, the questions as to what factors determine economic growth and what is the long-term relationship among these factors being devoid of any spurious correlation is very stimulating. In this paper we derive an empirical relationship for India between output, private investment, exports, school enrolment rate (as a proxy for human capital), real interest rate, government investment expenditure, real domestic credit to the private sector (over the period 1950-51 to 1995-96) using multivariate cointegration modelling. The aim is to use Johansen's (1998) cointegration technique, to find the long-run linear relationships entering the growth equilibrium of the Indian economy. The following section will trace the analytical framework and the methodological issues behind long-term growth. The third section presents econometric evidence for the factors determining output growth. The last section concludes. 


\section{Analytics of economic growth}

The concept of economic growth is central to the policy strategies of most DEs. Even at the very early stage of adapting Keynesian macroeconomic thinking to the problem of economic development, the consensus by planners was to concentrate on long-term growth in DEs rather than short-term stabilization (Rao, 1952). The concept of 'growthoriented adjustment' or the notion that economic growth is essential for the achievement of the twin goals of a sustained reduction in inflation and viable balance of payments (BOP), has in the last decade received the attention of policy makers and academics alike (Khan et al., 1991). Growth-oriented adjustment is a key characteristic of the policy packages that make up fund-supported market-based reform programmes, which are part and parcel of the macroeconomic policies currently underway in many DEs.

\section{Neoclassical model with endogenous growth}

Long before the neoclassical theories, the most popular model of economic growth was the so-called Harrod-Domar model, which made the first important contribution to aggregate growth theory. These aggregate growth models were extended in the 1950s and 1960s, with Solow's classic articles playing a leading role. Solow (1956) showed that the rates of saving and population growth, taken exogenously by assuming a standard neoclassical production function with decreasing returns to capital, determine the steady-state level of income per capita, which is exogenous. These exogenous neoclassical growth models have been extended in the late 1980s and early 1990s to endogenous growth models (Romer, 1986; Lucas, 1988; Rebelo, 1991).

The endogenous growth models developed by Lucas-Romer challenged the old neoclassical model by emphasizing the role of endogenous factors (i.e., human capital stock and $R \& D$ activities) as the main engines of economic growth. While early neoclassical models assumed total factor productivity growth (or technical progress) as exogenously given, the newer endogenous growth models attributed this component of growth to the 'learning by doing' effect occurring between physical and human capital, which results in increasing returns to scale in production technology (Lucas, 1988). The most distinctive difference between neoclassical exogenous and endogenous growth theories is that the former assumes constant returns to scale whereas the latter generally assumes increasing returns to scale. The assumption of increasing returns to scale provides a possible way to long-run sustained growth in endogenous growth theories. These theories of endogenous economic growth stress the point that the opening up of investment opportunities under a liberalized market-friendly economy brings about high economic growth. Besides, the World Bank gap model, which is offered as an alternative framework for growth, hypothesizes that growth of real output is related to the total investment, where investment is considered as one of the demand factors in determining growth.

To assess the relevance of these neoclassical models, we need first to come up with a definition of a model of development. If the goal of growth theory is to show the mechanism by which growth takes place, taking note of the demand side, then the new growth theory (endogenous) falls short. There is no 'demand' proper in these models. 
Two questions follow from this: (1) without effective demand how does one talk of actual growth? What does 'potential' or 'warranted' mean in observable terms? What sort of comparison with 'actuality' can one make on this basis? (2) Is it sensible to talk of 'endogenous' growth leaving the demand side out of the picture, when GDP growth has largely been demand-constrained in recent years, for example the demand shock during the Asian financial crisis of 1997-98 resulting from loss of consumer and business confidence. Hence there is room for more theoretical exploration in explaining the growth processes by considering both the demand and supply aspects (for a theoretical exploration in this direction see, for example, Palley, 1996). In neoclassical models, capital accumulation continued to be driven by household savings behaviour rather than firms' investment spending, and there was no role for aggregate demand factors. The inclusion of an investment function would then create a point of entry for aggregate demand factors, for investment being both a demand and a supply phenomenon.

A wide range of endogenous growth models have treated human capital as a critical factor in determining growth rate of output (see Lucas, 1988). The Lucas-Romer endogenous growth model suggests that endogenously accumulated human capital has a direct impact on the productivity of labour and, as a result, human capital becomes specific to the individual, leaving innovation in the stock of knowledge as an exogenous factor. It is an important source of long-term growth, either because it is a direct input into research (Romer, 1990) or because of its positive externalities (Lucas, 1988; Becker et al., 1990), and policies that enhance public and private investment in human capital promote long-term economic growth. The inclusion of human capital variables in endogenous growth models are intended to capture quality differences in the labour force, as nonphysical capital investment increases the productivity of the existing labour force. They commonly relate to education and are measured by an index of educational attainment, by mean years of schooling or by school enrolment. Secondary school enrolment is the variable most commonly used in endogenous growth studies, and it is also adopted here. Microeconomic studies for numerous DEs have found that individuals with higher levels of education tend to have relatively higher earnings (for further details, see Levin and Raut, 1997). Educational investment may also contribute indirectly to economic growth by reducing fertility and improving health and life expectancy.

The endogenous growth literature on finance and development posits a symbiotic relationship between the evolution of the financial system and development of the real economy, as financial development may promote productivity growth as a result of better screening and monitoring. Domestic credit can affect economic activity in many ways. It may contain at least two types of information about the process of financial intermediation. First, changes in credit may reflect an inability of financial intermediaries to make loans, perhaps because of changes in monetary policy. In this case, firms unable to issue debt in the open market may become credit-constrained leading to lower levels of investment and job creation. Secondly, changes in credit may reflect shocks to the intermediation system itself. Financial deregulation, financial innovations, or changes in the solvency of borrowers or lenders have implications for economic activity that may be transmitted through changes in the quantity of credit. Further, the sine qua non of financial liberalization in practice has been a significant increase in interest rates, as we always observe an increase in practice. The resultant 
increase in interest rates in the official market decreases the quantity of finance available to firms because it draws resources out of the unorganized market, and it is less efficient in intermediation because of the prevalence of high reserve requirements. For example, King and Levine (1993) present a model in which financial-sector taxes, such as deposit rate ceilings or high reserve requirements, have a negative effect on financial intermediation and, consequently, on innovative activity and economic growth. Moreover, the rise in real interest rates increases the cost of borrowing and decreases investment. Thus, the effect on growth is expected to be negative as the real interest rate captures the credit/capital cost of investments.

\section{Export-led model of growth}

Another major economic policy strategy advocates export-led growth, and there is considerable empirical evidence suggesting that growth has indeed been export-led in the most rapidly developed DEs. Moreover, there is recognition that India is a dependent economy in which the supply side of real output is constrained by the inadequate availability of foreign exchange. In international trade theory, a number of reasons have been advanced about why exports could serve as the engine of growth. It has been argued by a number of economists that a highly satisfactory performance on the export front by a number of DEs has been the result of a high rate of economic growth achieved by them as an outcome of skilful management of their economic policies. The relationship between exports and economic growth seems to be one of interdependence, such that one affects the other. There are substantial grounds for believing that there is a causal relationship between exports and economic growth, and that this relationship is one of interdependence rather than of unilateral causation. There are also grounds for believing that exports are a key factor in promoting economic growth and that it is generally a rise in exports that stimulates an increase in aggregate economic growth, rather than vice versa.

Many of the earliest studies (Maizels, 1968; Michaely, 1977; Balassa, 1978; Heller and Porter, 1978) concentrated on correlations between exports and income; aggregate production functions that included exports as an explanatory variable then followed (Tyler, 1981; Feder, 1983; Ram, 1985). Next came studies employing causality tests (Jung and Marshall, 1985; Bahmani-Oskooee et al., 1991) followed by the determination of causation using cointegration and error correction techniques (Bahmani-Oskooee and Alse, 1993; Ghatak and Price, 1997) and VAR methodology (Mallick, 1995; Henriques and Sadorsky, 1996). However, to postulate a uniform relationship between export growth and economic growth among countries is unrealistic, given the considerable differences in economic structure exhibited by DEs. This uniformity is susceptible to a wide range of criticism including the nonexistence of balanced growth paths (Quah, 1993), the sensitivity of the results to the set of conditioning variables (Levine and Renelt, 1992), the heterogeneity of slope coefficients across countries, the likely differences in causality patterns and cross-sectional endogeneity of regressors, and the standard measurement and statistical problems (see Arestis and Demetriades, 1997).

It has been mentioned in the literature that export growth and income growth are positively related. In either case, import growth can act as an intervening variable because some of the Indian industries are import-intensive in nature, and macroeco- 
nomic policies are always aimed at keeping the BOP position within reasonable limits to maintain a stable exchange rate. Imports of raw material and intermediate inputs can be taken as one of the supply factors in the growth process. However, Ghatak and Price (1997) find that imports do not appear to be important to Granger cause output in the case of India. Aside from that, since price fluctuations and political intervention influence economic growth to some extent, to control for these factors the real interest rate surprises are included. The reason is that growth is highly sensitive to favourable or unfavourable real interest rate movements. Moreover, the real interest rate is an especially important variable because changes in real interest rate have an impact on investment in opposite directions. On the one hand, it affects investment positively through increasing financial savings and the supply of credit to the investors (McKinnon/Shaw framework). On the other hand, the real interest rate affects investment negatively since it captures the price of credit/capital (Keynesian/structuralist approach).

Technically, the ideas in such a complicated set-up can be presented simply, as below. Following the standard endogenous growth approach (Rebelo, 1991), a given country's production can be characterized by the augmented aggregate production function as

$$
\begin{gathered}
Y_{t}=A_{t} K_{t}^{\gamma} K_{t}^{\theta}(H L)_{t}^{\eta} \quad \gamma+\theta+\eta>1 \text { for endogenous growth } \\
A_{t}=X_{t}^{\phi}(\mathrm{RIR})_{t}^{\lambda}(\mathrm{RDCP})_{t}^{\omega} \text { and } H L=E^{\delta}
\end{gathered}
$$

where $Y$ is real output; $K p$ and $K g$ denote the physical private- and public-sector capital stock, respectively; $H L$ is the average level of human capital indicating skilled labour, which is more likely to improve productivity; $A$ is total factor productivity; $E$ is the measure of education level; $\delta$ is the return to level of education; $X$ is exports; RIR is real interest rate; RDCP is real domestic credit to the private sector; $\gamma, \theta, \eta, \phi, \lambda$, and $\omega$ are elasticity parameters of private and public capital stocks, human capital, real expoxrts, real interest rate and real domestic credit to the private sector, respectively.

The RIR is defined as nominal deposit rate minus the inflation rate. X, RIR and RDCP are not proper arguments of the standard production function approach in that they are not production inputs, however they are intended to reflect those international and domestic factors that influence productivity but are not captured in $L$ or $K$. So total factor productivity $(A)$ is determined by exports, real interest rate and RDCP. Given the relatively low level of openness of the Indian economy, the output response of expansionary monetary policy through the channels of interest rates or credit is stronger and more persistent than the exchange rate channel (Reserve Bank of India (RBI), 1999). In the present exercise, neither the real exchange rate nor the terms of trade were found to be crucial in providing a stable VAR model, so we excluded those variables from our model.

Assuming both types of capital stock depreciate at the same rate at $\psi$, the evolution of $K p$ and $K g$ is given by the following:

$$
\dot{K} p=I p-\psi K p \text { and } \dot{K} g=I g-\psi K g
$$

where $I p$ and $I g$ denote private and public investments, respectively. In steady state $\dot{K} p=\dot{K} g=0$ and two types of capital stock converge to $\mathrm{Kp}^{*}$ and $\mathrm{Kg}^{*}$. That is, 


$$
K p=\frac{1}{\psi} I p \text { and } K g=\frac{1}{\psi} I g .
$$

Substituting this in the production function and taking logs gives the following longterm output model:

$$
\text { In } Y_{t}=\frac{\gamma}{\psi} \operatorname{In} \mathrm{PVTCF}_{t}+\frac{\theta}{\psi} \operatorname{In} \mathrm{PUBCF}_{t}+\eta \delta \operatorname{In} E_{t}+\phi \operatorname{In} X_{t}+\lambda \operatorname{In} \mathrm{RIR}_{t}+\omega \operatorname{In} \mathrm{RDCP}_{t}
$$

where PVTCF is private investment and PUBCF is public investment.

In equilibrium we assume that the process of capital accumulation is investmentdriven, recognizing saving as a residual that adjusts to accommodate the level of investment spending. Gross private capital formation describing physical endowments is the most common variable in studies of endogenous growth. Investment, as opposed to the accumulated stock of capital, can be used because it is an important vehicle for technological diffusion because of the vintage effect of new capital. Further, during fiscal adjustments, government capital spending is indeed reduced more than other categories of government spending and this decline in public capital spending has important growth-retarding effects. Hence a structural feature that can be incorporated here is the 'crowding-in' hypothesis, which assumes that there is complementarity between government and private investment. Thus, it is necessary to decompose total investment into private and public investment, as public investment on infrastructure is treated as an engine of growth. The other structural variables are the real interest rate and real domestic credit to the private sector.

Given the linkages among the variables that make output growth possible, it would be better to use the multivariate theory of cointegration, where all variables in the VAR system are supposed to be dynamically related. This is precisely because of the limitations of the econometric evidence that is often put forward in support of crosscountry growth studies. For instance, in many studies all or most DEs are treated as alike and country-wise cross-section data used. Countries differ from one another with respect to their size, level of skill of their labour force, infrastructure, the role of the state, stability and type of governance, etc. As such, the statistical evidence gathered can not be taken as representing any one DE. In other cases the econometric evidence is offered in terms of structural econometric models with time-series data. But such models ignore the nonstationary nature of the data, which are known to give spurious results and hence cannot be taken seriously (see Nelson and Plosser, 1982; Perron, 1988).

\section{Empirical analysis}

In this section the empirical results are presented. Economic growth is measured in terms of real Gross Domestic Product (GDP). Annual data on real GDP at factor cost (GDPFC), real gross domestic private capital formation (PVTCF), real exports at constant (1980-81) prices as a percentage of GDP (EXPG), real public investment expenditure (PUBCF), domestic credit to the private sector and interest rate from 1950-51 to 1995-96 have been compiled from various issues of the Economic survey, Government of India (GOI), and the Report on currency and finance, RBI, respectively. 
Higher secondary school enrollment (SERAT) has been obtained from the Handbook of educational and allied statistics (GOI, 1987); Selected educational statistics (various volumes; GOI); and Education in India, Vol. I (various years; GOI). Figure 1 plots the logarithms of the seven time series and the change in the log of the variables. All series exhibit strong upward trends, except RIR, which is stationary and EXPG, which is volatile, reflecting possible effects of trade policy.

The econometric applications are necessarily driven by economic theories, which give rise to econometric relations of a structural type. Since most of the macroeconomic time series are nonstationary, it is now quite well known that the traditional structural equations portray spurious correlations and erroneous conclusions (Granger and Newbold, 1974; Phillips, 1986). As a precondition for cointegration, the individual series are tested for a common order of integration and then the Johansen maximum likelihood method is applied to find the cointegrating vectors (Johansen, 1988, 1991).

\section{Testing for stationarity}

Here we examine the individual series using graphical evidence to demonstrate the normality of the data density function (Figure 2), and we test for the integrated properties of each series with ADF tests for existence of unit roots (Table 1). The essence of the ADF tests is the null hypothesis of nonstationarity, the rejection of which requires
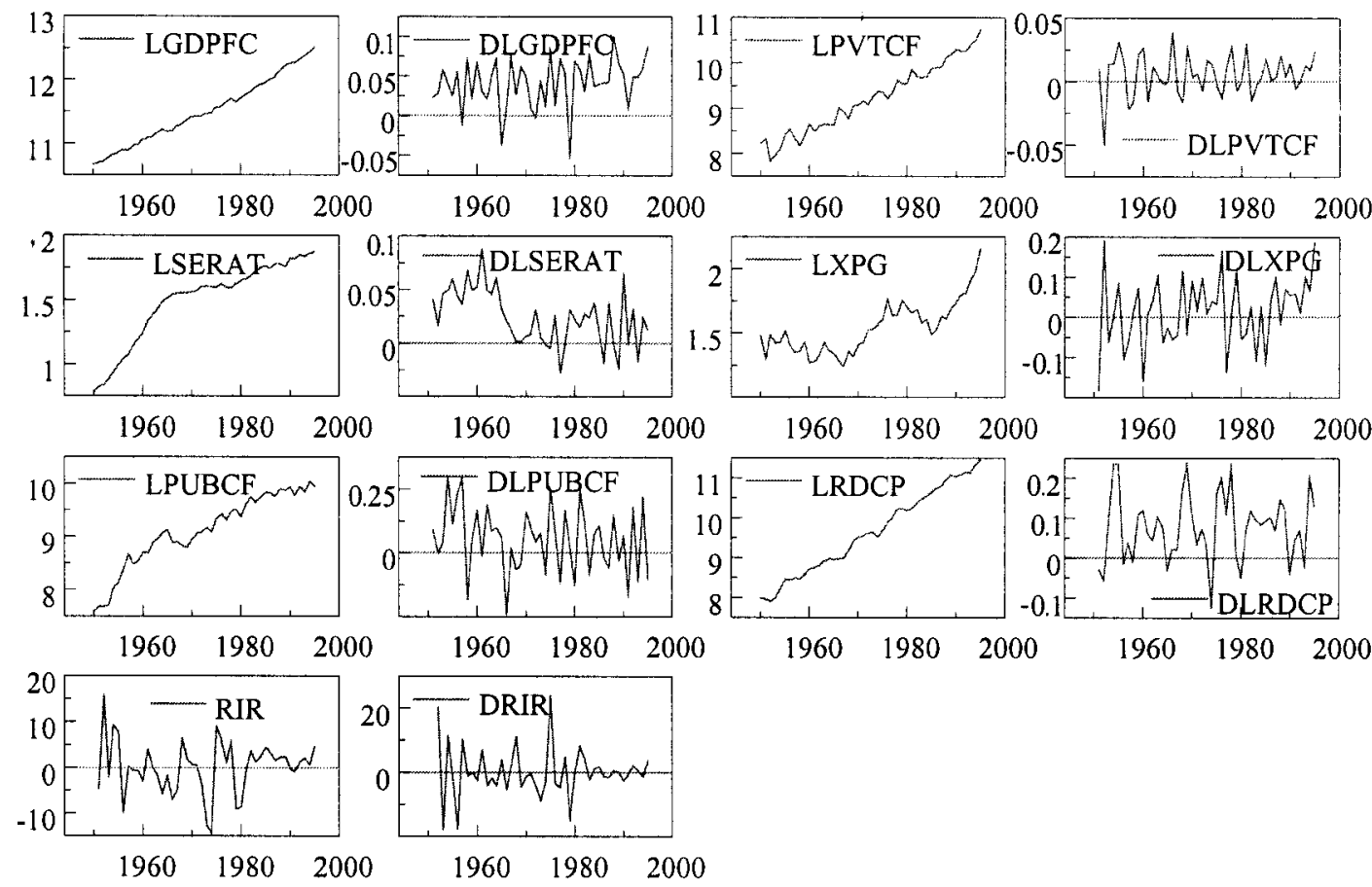

Figure 1 Levels and first differences of the variables 


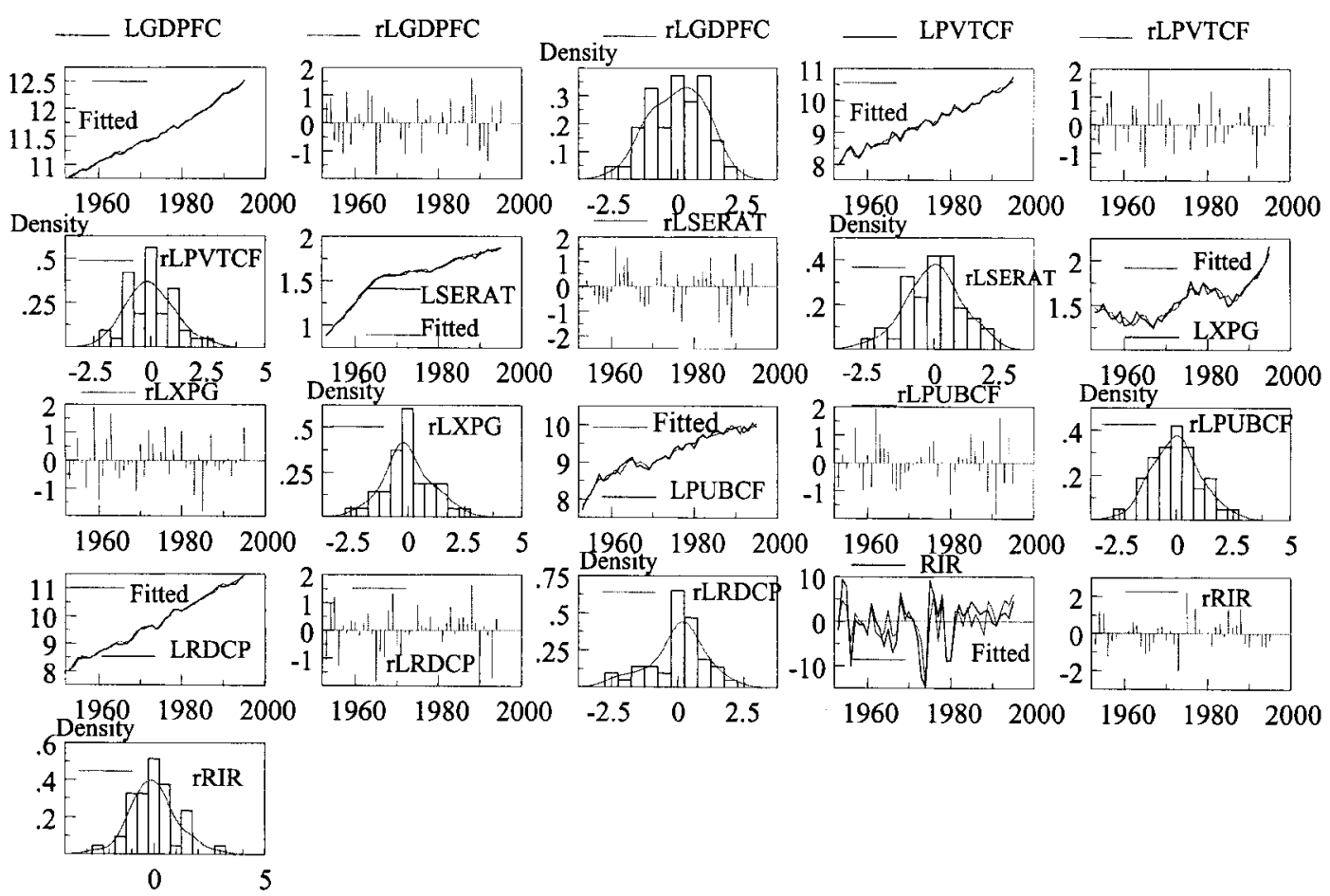

Figure 2 Graphical diagnostics - fitted and actual values and scaled residuals of the variables

a negative and significant test statistic. The ADF statistics are calculated as the $t$-ratios of the coefficient on $x_{t-1}$ (i.e., $\left.\tau_{1}\right)$ in the equation below:

$$
\Delta x_{t}=\tau_{0}+\tau_{1} x_{t-1}+\tau_{2} T+\sum_{i=1}^{k} \varphi_{i} \Delta x_{t-i}+\varepsilon_{t}
$$

Where $x$ is a variable, $T$ is a linear time trend, $k$ is the order of augmentation of the test and $\varepsilon$ represents the residuals. Here, we examine each time series to determine if it is stationary or nonstationary employing the unit root tests (for an overview of unit-root tests, see Hendry, 1995). If a time series is found to be nonstationary, we next examine if its first difference is stationary. Using this procedure we determine the order of integration of a time series. Table 1 presents the results of ADF test statistics for the log levels and first differences of the logs of the annual time-series data for India for the period 1950-1995. From Table 1 it is evident that all time series, except real interest rate, are integrated of the order of one in levels, i.e., stationary in first-differences based on the ADF test. In selecting the order of the ADF test, we follow Dickey et al. (1986) who have argued that the choice of additional lags, i.e., value of $k$, could be determined by the level of significance of estimated lag coefficients using the standard $t$-test. The results are compatible with the hypothesis that nonstationarity characterizes the variables in this study. 
Table 1 Testing for unit root

\begin{tabular}{llllll}
\hline Variables & \multicolumn{3}{c}{ ADF } \\
\cline { 2 - 3 } & \multicolumn{3}{l}{ Levels } & & \multicolumn{2}{l}{ First differences } \\
\cline { 2 - 3 } \cline { 5 - 6 } & Without trend & With trend & & Without trend & With trend \\
\hline LGDPFC & 1.5726 & -0.55135 & & $-5.4004^{* *}$ & $-5.9361^{* *}$ \\
LPVTCF & -0.3391 & $-6.2306^{* *}$ & & $-8.1855^{* *}$ & $-8.1249^{* *}$ \\
LXPG & 1.0797 & -0.97095 & & $-4.4481^{* *}$ & $-4.9690^{* *}$ \\
LPUBCF & -2.5916 & -2.9774 & & $-5.1742^{* *}$ & $-5.7775^{* *}$ \\
LSERAT & $-3.2548^{*}$ & -2.5779 & & -2.4619 & -3.2676 \\
LRDCP & -0.48216 & $-3.9984^{*}$ & & $-5.8744^{*}$ & $-5.8047^{* *}$ \\
RIR & $-4.4984^{* *}$ & $-4.4953^{* *}$ & $-7.5394^{* *}$ & $-7.5745^{* *}$ \\
\hline
\end{tabular}

Notes: ${ }^{* *}$ and ${ }^{*}$ indicate significance at $1 \%$ and $5 \%$ level, respectively; numbers reported in the table are $t$-values of $\tau_{1}$ and the ADF unit root test is based on one lag.

\section{Cointegration and short-run dynamics}

Given the presence of the unit root in each series, a precondition for the existence of a stable steady state relationship is some linear combination of these variables, implying cointegration. Even if ADF tests indicate some series are stationary, they can still be included in a VAR analysis (see Hendry, 1995). The VAR approach has the advantage of making all variables explicitly endogenous. All these problems concerning nonstationarity and cointegration of the data may be solved by employing Johansen's maximum likelihood (ML) method (Johansen, 1988, 1991) in which an error correction mechanism is also included.

The Johansen method is a multivariate method, which starts with an unrestricted VAR representation as:

$$
y_{\mathrm{t}}=\mu+\sum_{i=1}^{k} \Pi_{i} y_{t-\mathrm{i}}+\varepsilon_{t}
$$

where $y_{t}$ contains all $N$ variables of the model, $\Pi$ is the $N \times N$ matrix of parameters, and $\varepsilon_{t}$ is a vector of random errors and is distributed as $N\left(0, \sigma^{2} V\right)$.

The VAR model can be represented in terms of first differences as follows:

$$
\Delta y_{t}=\mu+\sum_{i=1}^{k-1} \Gamma_{i} \Delta y_{t-i}+\Gamma_{k} y_{t-k}+\Psi x_{t}+\varepsilon_{t}
$$

where $\Gamma_{i}=-I+\Pi_{1}+\ldots+\Pi_{i}$ ( $I$ is a unit matrix), $y=$ [LGDPFC, LPVTCF, LSERAT, LXPG, LPUBCF, LRDCP, LRIR], $x=$ [DUM73, DUM79]. Dummy variables for 1973 and 1979 are included to capture the impact of two oil price shocks. All the variables have been entered logarithmically.

The Johansen method uses a maximum likelihood (ML) estimate of the above multi- 
variate system. The rank $(R)$ of $\Gamma_{k}$ (which is a $N \times N$ matrix) can at most be equal to $N$, in which case all variables in $y_{t}$ are integrated of order zero (i.e., the variables constituting the vector process $y_{t}$ are not cointegrated). If the rank of $\Gamma_{k}$ is equal to $R<N$, then $R$ indicates the number of cointegrating vectors and there exists a representation of $\Gamma_{k}$ such that $-\Gamma_{k}=\alpha \cdot \beta^{\prime}$, where $\alpha$ and $\beta$ are $N \times R$ matrices. The maximum likelihood estimates of $\alpha$ and $\beta^{\prime}$, after normalization, can be interpreted as the adjustment matrix and the matrix of cointegrating vectors (long-term multipliers), respectively. Johansen has proposed two likelihood ratio test statistics to test the null hypothesis on the number of cointegrating vectors, both of which are based on the number of significant eigenvalues of $\Pi$ : the maximal eigenvalue and the trace statistic. A test of zero restrictions on $\alpha$ is the test of weak exogeneity when the parameters of interest are long-term. Toda and Phillips (1994) interpret weak exogeneity in a cointegrated system as a notion of long-term causality. We employ weak exogeneity tests to examine the issue of longterm causality between the variables in the system.

The Johansen ML method is applied to the VAR formed by the seven variables. The lag length included in the VAR is two (we adopt the sequential reduction method of VAR lag length selection recommended by Doornik and Hendry (1997) starting from maximum two lags with annual data. The testing begins with a comparison of a twolag model with a one-lag model. The null hypothesis that the second lag is equal to zero is rejected). The system diagnostics are presented in Table 2, which satisfies the assumption of normality, no auto-correlation and no errors in the residuals. The results are obtained using PcFiml version 9.00 (see Doornik and Hendry, 1997), which are presented in Table 3 . It reports the $\lambda_{i}$ eigenvalues, the $\lambda$-max and the trace statistics (both adjusted and not adjusted for degrees of freedom), and the $5 \%$ critical values. The test statistics indicate that the hypothesis of two cointegrating vectors cannot be rejected. Hence, there are two long-term relationships, which can be thought of as longterm output and private investment equations. Both $\lambda$-max and trace statistics support the existence of two vectors at a $1 \%$ level of significance. In addition, a visual inspection of vector 1 and vector 2 in Figure 3 also confirms the existence of two cointegrating relationships because they are stationary around the zero-mean. Table 4 reports the normalized $\beta$ eigenvectors and the corresponding $\alpha$ coefficients. Having obtained the cointegrating relations, we need to test which variables are exogenous by imposing zero-restrictions on the adjustment coefficients in the following adjustment vectors denoted as $\alpha_{1}=\left[\alpha_{11}, \alpha_{12^{\prime}} \alpha_{13^{\prime}}, \alpha_{14^{\prime}}, \alpha_{15^{\prime}}, \alpha_{16^{\prime}} \alpha_{17}\right]$, and $\alpha_{2}=\left[\alpha_{21}, \alpha_{22^{\prime}}\right.$ $\alpha_{23}, \alpha_{24}, \alpha_{25}, \alpha_{26}, \alpha_{27}$. The outcome of the tests of hypotheses about the adjustment

Table 2 Diagnostic test statistics for individual equations and the VAR

\begin{tabular}{lllllll}
\hline Variables & AR 1-2 & \multicolumn{3}{c}{ Normality $\chi^{2}$} & \multicolumn{3}{l}{ ARCH(1) } \\
\hline LGDPFC & 1.135 & {$[0.3381]$} & 0.73375 & {$[0.6929]$} & 0.98564 & {$[0.3307]$} \\
LPVTCF & 2.1049 & {$[0.1438]$} & 1.13 & {$[0.5684]$} & 0.40095 & {$[0.5326]$} \\
LSERAT & 0.5483 & {$[0.5850]$} & 0.88742 & {$[0.6417]$} & 0.018699 & {$[0.8924]$} \\
LXPG & 2.6584 & {$[0.0906]$} & 0.98864 & {$[0.6100]$} & 0.19874 & {$[0.6597]$} \\
LPUBCF & 0.78731 & {$[0.4665]$} & 0.6855 & {$[0.7098]$} & 1.0953 & {$[0.3057]$} \\
LRDCP & 2.2743 & {$[0.1246]$} & 2.7207 & {$[0.2566]$} & 0.32399 & {$[0.5745]$} \\
RIR & 1.3117 & {$[0.2880]$} & 3.4221 & {$[0.1807]$} & 0.64448 & {$[0.4300]$} \\
System & 1.1441 & {$[0.3101]$} & 12.5 & {$[0.5662]$} & - & \\
\hline
\end{tabular}


coefficients reveals that LXPG, LRIR, LRDCP, LPUBCF are weakly exogenous. The weak-exogeneity tests are reported as follows:

LR-test, $\alpha_{13} \& \alpha_{23}: \chi^{2}(2)=0.34031 \quad[p=0.8435] \quad$ LR-test, $\alpha_{14} \& \alpha_{24}: \chi^{2}(2)=2.3187 \quad[p=0.3137]$

LR-test, $\alpha_{15} \& \alpha_{25}: \chi^{2}(2)=2.751 \quad[p=0.2527] \quad$ LR-test, $\alpha_{16} \& \alpha_{26}: \chi^{2}(2)=4.0106 \quad[p=0.1346]$

LR-test, $\alpha_{17} \& \alpha_{27}: \chi^{2}(2)=16.952 \quad[p=0.0002] \quad$ LR-test, $\alpha_{13}$ to $\alpha_{26}: \chi^{2}(8)=7.7845 \quad[p=0.4548]$.
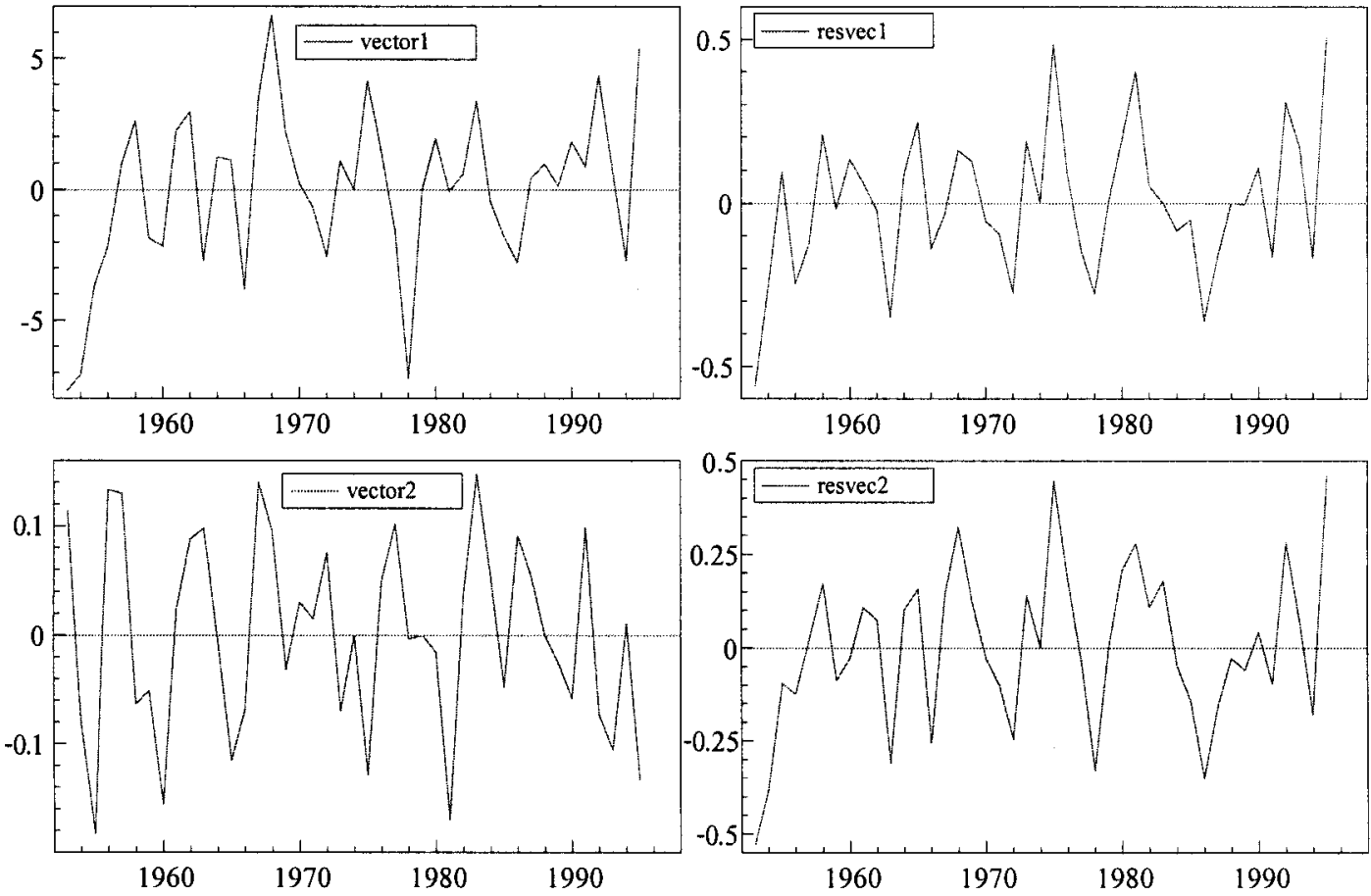

Figure 3 Cointegration vectors: unrestricted and restricted

Table 3 Testing for cointegration - the Johansen method

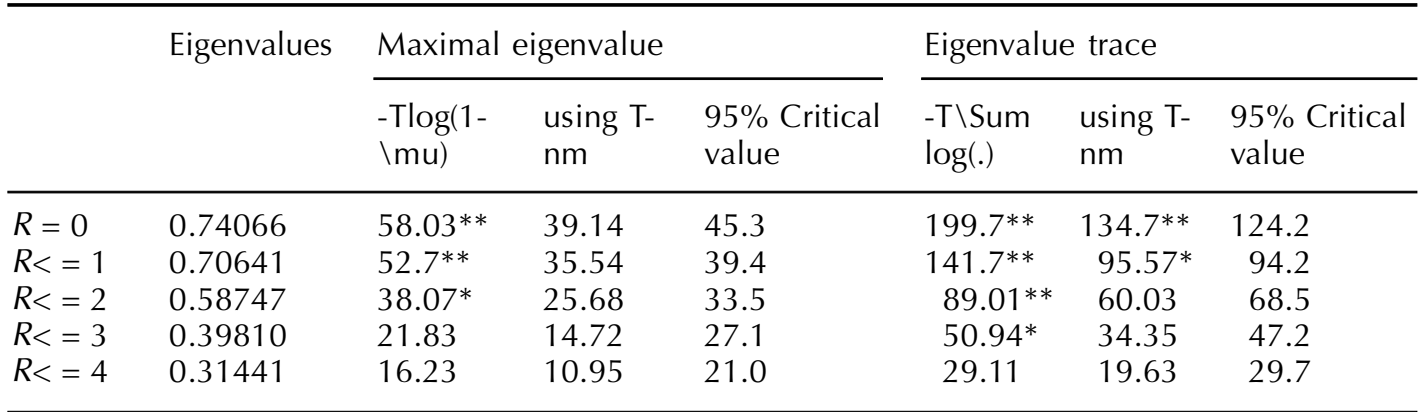

Note: $R$ is the number of cointegrating vectors; ${ }^{* *}$ and ${ }^{*}$ means significance at $1 \%$ and $5 \%$ level, respectively. 
Table 4 The Johansen method: normalized $\beta$ eigenvectors and $\alpha$ adjustment coefficients

\begin{tabular}{lccccccc}
\hline & LGDPFC & LPVCF & LSERAT & LXPG & LPUBCF & LRDCP & RIR \\
\hline $\begin{array}{l}\text { Cointegration } \\
\text { coefficients }\end{array}$ & 1.0000 & 23.775 & -11.330 & -13.488 & 2.1883 & -12.452 & -0.6232 \\
& -1.0302 & 1.000 & 0.229 & -0.076 & 0.1642 & -0.356 & 0.0325 \\
Adjustment & 0.0013 & -0.021 & -0.0007 & 0.005 & -0.0096 & -0.006 & 0.7381 \\
parameters & -0.0319 & -0.858 & -0.0206 & -0.065 & -0.1584 & -0.092 & -23.974 \\
\hline
\end{tabular}

Now, we need to test hypotheses about the cointegration vectors by identifying them. Denoting the two long-term equilibrium relationships by $\beta_{1}=\left[\beta_{11}, \beta_{12}, \beta_{13}, \beta_{14}\right.$, $\left.\beta_{15}, \beta_{16}, \beta_{17}\right]^{\prime}$ and $\beta_{2}=\left[\beta_{21}, \beta_{22}, \beta_{23}, \beta_{24}, \beta_{25}, \beta_{26}, \beta_{27}\right]$ ', respectively, we impose the following restrictions for exact identification: $\beta_{1}=\left[1, \beta_{12}, \beta_{13}, \beta_{14}, \beta_{15}, 0, \beta_{17}\right]^{\prime}$ and $\beta_{2}=\left[0,1, \beta_{23}, \beta_{24}, \beta_{25}, \beta_{26}, \beta_{27}\right]$ '. The restrictions on $\beta_{1}$ indicate an equation for output. For exact identification, we impose $\beta_{11}=1$ and $\beta_{16}=0$ because LRDCP affects output indirectly through private investment. Theoretically the second vector must be interpreted as an investment function in order to have a complete model in which aggregate demand factors would play an important role in generating growth. The restrictions we impose to identify the second vector are $\beta_{22}=1$ and $\beta_{21}=0$ to get an equation for private investment. The over-identifying restrictions are the coefficients associated with exports: $\beta_{14}=0$ and $\beta_{24}=0$. Moreover it has been well documented in the literature that output has never been export-led in India. In the present context, we are mainly interested in whether exports can be excluded from the cointegrating relations. We want to impose this restriction just to test the hypothesis that export is weakly exogenous and has not influenced output growth in India. We test the theoretical restriction to determine whether there is export-led growth or growthdriven exports in the long-term output equation. The hypothesis that exports do not enter cointegrating relationships between the other variables cannot be rejected. The likelihood ratio (LR) test statistic for testing the two $\beta$ with eight $\alpha$ restrictions is distributed as $\chi^{2}(10)=14.172$ [0.1653], which is accepted. This implies that export is exogenous and has not influenced output in the long run. In other words, there has been no export-led growth in India. The following two restricted cointegrating relationships are obtained: $\mathrm{LGDPFC}=0.21773^{*} \mathrm{LPVTCF}+0.63966^{*} \mathrm{LSERAT}+0.16661^{*}$ LPUBCF $+0.083522^{*}$ RIR and LPVTCF $=0.4475^{*}$ LSERAT $+0.0132^{*} \mathrm{LPUBCF}+0.515^{*}$ LRDCP+0.06138*RIR.

These two long-term equations, determining levels of real output and private investment, constitute the real output sector. Since the coefficients associated with investment and human capital variables add up to greater than unity $\left(\beta_{12}+\beta_{13}+\beta_{15}>1\right)$, there is basis for confirming the presence of endogenous growth, and the 'learning by doing' effect does appear to cause India's economic growth to have a rapid and sustained growth. Therefore India's economic growth can be described by an endogenous growth model and investment in human capital should be considered as a crucial factor for economic growth. Moreover, it substantiates the Keynesian belief that 
it is investment behaviour that determines the extent to which household savings are realized in the form of capital accumulation. The hypothesis that government investment crowds out private investment is not true, as the crowding-in factor is strictly positive. There is also a complementarity relation between human capital and private capital formation. An explanation of the inability on the part of exports to increase economic growth may be that, in the case of the Indian economy, the percentage change in imports owing to $1 \%$ change in income is quite high. We plot the restricted cointegrating relations in Figure 3, which look very much same as the unrestricted one.

The results exhibit strong cointegration among the variables and the relationship constitutes a stationary time-series with a constant mean. But cointegration implies that there exist ECMs of the above cointegrating equations. Given that all the variables are weakly exogenous except output, private investment and real interest rate, we need to model $\triangle$ GDPFC, $\triangle$ LPVTCF, $\triangle$ RIR jointly. Since RIR is not truly endogenous theoretically in this model, we model only short-run output and investment jointly. The results of the estimated ECMs are presented in Table 5. The ECMs are estimated using FIML with one-lag differences for all the variables. The general to specific method is used to find a parsimonious representation of the relationship; that is, variables are deleted from the most general specification using the LR-test of over-identifying restrictions. The diagnostic test statistics indicate that there is no evidence of serial correlation, of heteroscedasticity, of nonnormality of the residuals, and of mis-specification (see Table 5). From the evidence it is quite clear that India's economic growth in the short-term is influenced to a large extent by private investment on physical capital, public investment on infrastructure, which are significant in the ECM of $\triangle$ GDPFC.

The influence of $\Delta$ LRIR on change in output is mixed in the short run, negative in the

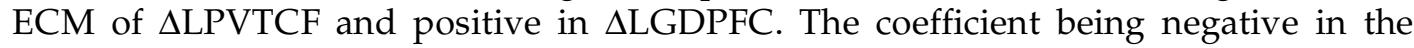
private investment equation can be interpreted as a Keynesian investment function where investment is negatively related to the real interest rate. This also corroborates the structuralist approach to investment (see Taylor, 1991) that lowering the interest rate will stimulate investment and economic growth in an economy where an organized financial market coexists with an informal credit market. In the presence of informal loan markets a rise in official interest rates may lead to a reduction in financial intermediation and have an adverse effect on output in the short and medium term. Essentially, this is because informal credit markets are more efficient at providing financial intermediation than the official commercial banking system, because operators in the informal markets are able to escape from government banking regulations (see, for example, van Wijnbergen, 1983). The estimate being positively siginificant implies that it supports a neoclassical model of the McKinnon-Shaw type. The coefficient of exports in the output equation is significant, indicating that exports are an important factor for growth in the short term. The coefficient of private investment with respect to change in output is significant, implying an accelerator process in the short term, and with respect to real domestic credit is positive and significant. Public investment has a crowding out effect on private investment via output in the short term.

It is evident that the ECM1 and ECM2 terms are highly significant, implying that output and private investment adjust in the short term to a disequilibrium in the longterm relationship. The parameter estimates indicate that investment adjusts fastest to a 
Table 5 FIML estimates of the ECMs

\begin{tabular}{|c|c|c|}
\hline & $\triangle \mathrm{LGDPFC}$ & $\Delta$ LPVTCF \\
\hline $\mathrm{ECM} 1_{t-1}$ & $-0.067023(-3.167)$ & $1.1709(8.025)$ \\
\hline $\mathrm{ECM} 2_{t-1}^{l-1}$ & $0.081684(1.533)$ & $-1.2160(-7.883)$ \\
\hline$\Delta$ LGDPFC $_{t-1}$ & $-0.27048(-1.809)$ & $1.1001(2.233)$ \\
\hline$\Delta$ LPVTCF $_{t}$ & $0.055143(1.049)$ & - \\
\hline$\Delta$ LPVTCF $_{t-1}$ & - & 0.47387 (3.639) \\
\hline$\Delta$ LSERAT $^{l-1}$ & - & $1.3019(2.481)$ \\
\hline$\Delta \mathrm{LXPG}_{t-1}$ & $0.11865(1.980)$ & - \\
\hline$\Delta \mathrm{LPUBCF}_{t-1}$ & $-0.073100(-2.197)$ & - \\
\hline$\Delta \mathrm{RIR}_{t}$ & $0.0019947(2.126)$ & $-0.0079216(-1.867)$ \\
\hline$\Delta \mathrm{RIR}_{t-1}$ & - & $0.010022(3.427)$ \\
\hline$\Delta \mathrm{LRDCP}_{t}$ & & $0.52240(2.057)$ \\
\hline$\Delta \mathrm{LRDCP}_{t-1}$ & $0.17892(2.396)$ & - \\
\hline DUM79 & $-0.087370(-3.038)$ & - \\
\hline Constant & $0.22732(1.435)$ & $-3.9496(-6.174)$ \\
\hline$\sigma$ & 0.0250585 & 0.0870837 \\
\hline $\operatorname{AR}(1-2) F$ & $2.1232 \quad[0.1472]$ & $2.2644 \quad[0.1048]$ \\
\hline$N(2)$ & $2.1094 \quad[0.3483]$ & 0.23104 [0.8909] \\
\hline$\chi^{2}$ & $2.3113 \quad[0.5104]$ & $3.5699 \quad[0.3118]$ \\
\hline $\mathrm{ARCH}(1)$ & $0.065295[0.8011]$ & $0.39522 \quad[0.5371]$ \\
\hline Vector $A R(1-2) F$ & & {$[0.1103]$} \\
\hline Vector N (6) & & $2.9386 \quad[0.5682]$ \\
\hline$\chi^{2} \operatorname{LR}(13)$ & & $11.6757 \quad[0.5544]$ \\
\hline
\end{tabular}

Notes: Figures in parentheses are $t$-values; numbers in square brackets are the probability values; $\sigma$ is the standard error of the regression; $\chi^{2} \operatorname{LR}(13)$ is the LR test of over-identifying restrictions.

disequilibrium in the long-term relationship, while the estimated coefficient on the ECM1 term in the output equation suggests a slow output adjustment. It may be noted that the negative and significant effect of the dummy variable (DUM79) in 1979 in the output ECM reveals an adverse effect of oil price shocks. It appears that the ECMs are well specified, as none of the diagnostic tests failed. The equations pass the LM test in their F-version, and Normality test for residuals distributed as $\chi_{2}{ }^{2}$. LM is the Lagrange multiplier test for serial correlation, which is asymptotically distributed as a chi-square test. The constancy of the model is accepted with almost every in-sample forecast lying well inside the individual 95\% confidence bars (see Figure 4). The one-step (ex post) forecast analysis 1991 to 1995 test values are given below.

Parameter constancy forecast tests:

$$
\begin{array}{lrl}
\text { using } \backslash \text { Omega } & \chi^{2}(10)=11.955[p=0.2881] \quad F(10,28)=1.1955[p=0.3353] \\
\text { using V[e] } & \chi^{2}(10)=10.289[p=0.4155] & F(10,28)=1.0289[p=0.4455]
\end{array}
$$

By carrying out dynamic simulations and impulse responses, the short-term model was found to be stable (see Figure 5). 

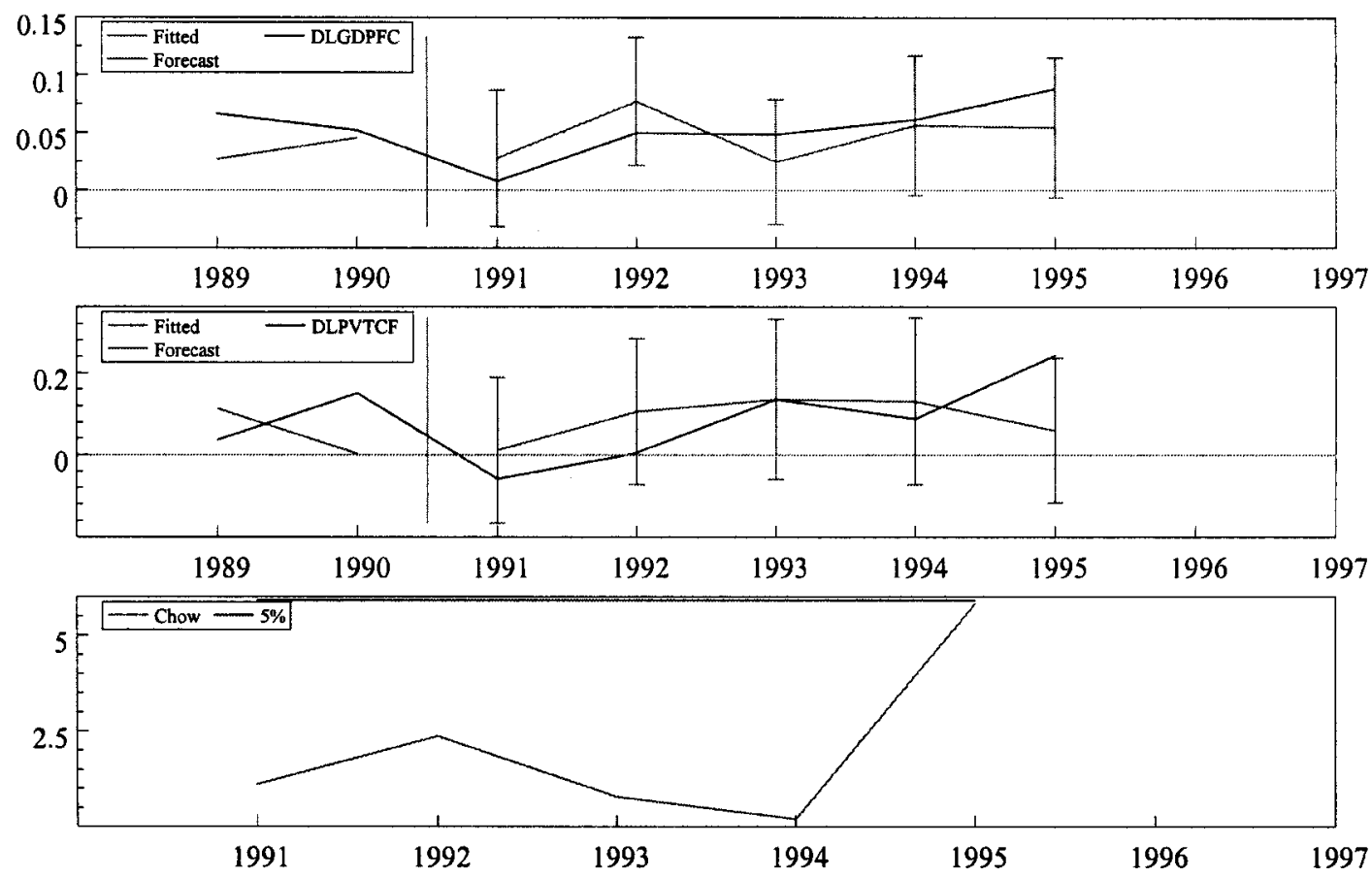

Figure 4 Dynamic model-based forecasts
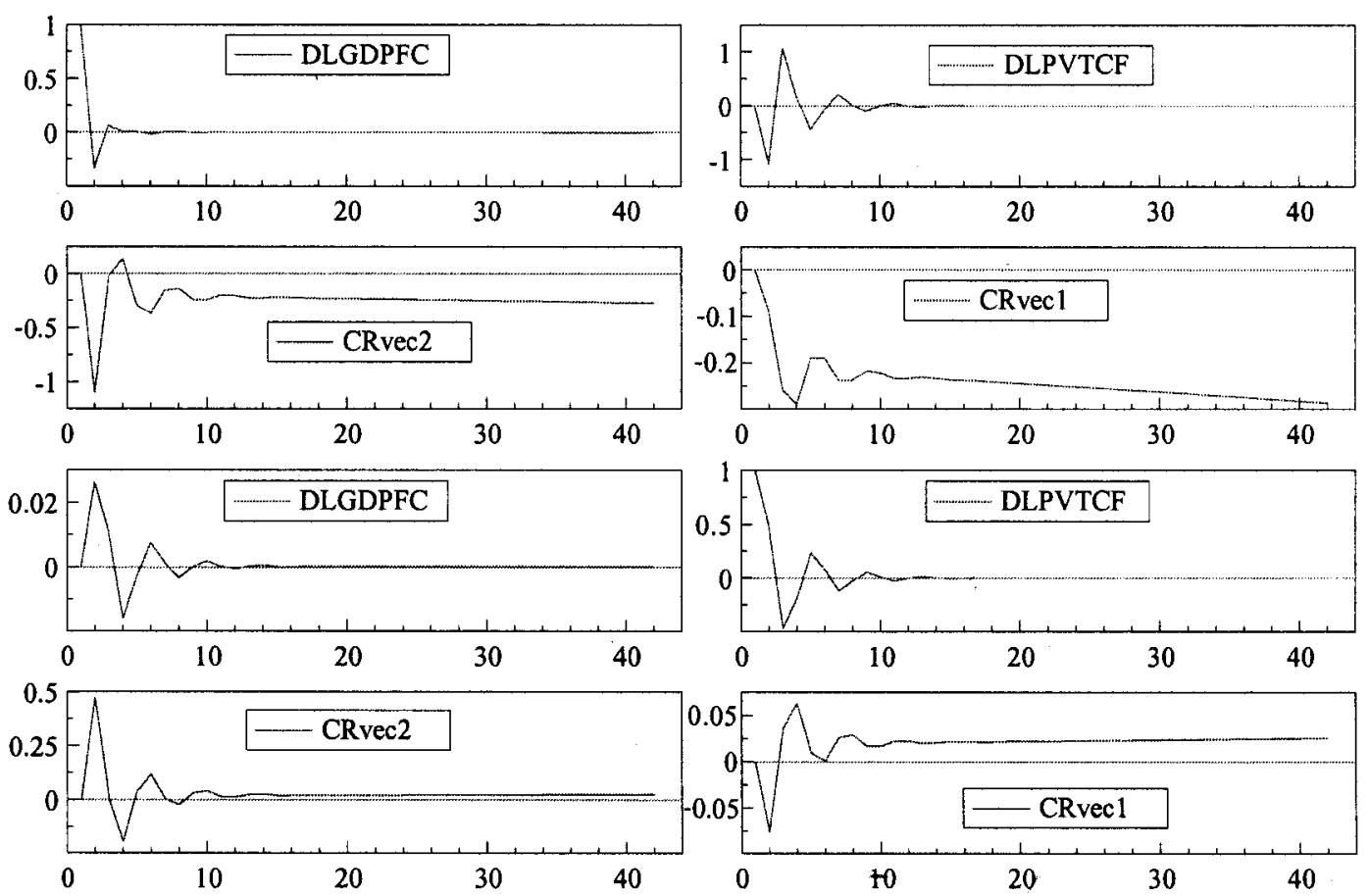

Figure 5 Dynamic simulation and impulse responses 


\section{Conclusion}

In this paper we have made an empirical attempt to join the theory of aggregate demand with the theory of endogenous growth. This contrasts with neoclassical growth theory in which the influences of aggregate demand are completely absent. We have examined the behaviour of demand and supply factors in explaining the long-term growth in India within the multivariate cointegration framework using annual data for the period 1950-51 to 1995-96. By performing the cointegration test for the existence of long-term relationships, we have found that there are two cointegrating vectors explaining output and private investment in the Indian context. The key factors to longterm growth are public investment, human capital, real interest rate and domestic credit to the private sector. Public investment appears to influence growth directly as well as indirectly via private investment, and cutting back public investment may seriously harm economic performance. The error correction models provide evidence to trace the short-run dynamics of the cointegrating vectors. The adjustment mechansims in the short run are supportive of investment-induced growth processes through private investment, which provides a demand-oriented explanation for long term growth.

In a restricted model, we have shown that there has been no export-led growth in India by performing weak exogeneity tests and imposing zero restriction on the coefficients of real exports in both the cointegrating relations during the sample period. In contrast to the export-push approach, the analysis here focuses on domestic demand as the engine of growth in the early stages of development. However, this finding is different from earlier findings in the sense that the present framework includes not only an export-led growth hypothesis but also an endogenous growth proposition in which capital accumulation is driven by investment spending by firms, not by the savings behaviour of households. Thus, the present exercise is a first empirical attempt of this kind in providing a demand-side explanation for the problem of long-term growth, highlighting the point that economic growth is determined not only by supply factors but also by demand factors.

\section{Acknowledgements}

This is a revised version of a chapter of my Ph.D. dissertation submitted to the University of Warwick, UK in 1998. Thanks are due to Kenneth F. Wallis, Jeremy Smith, Brigitte Granville and the anonymous referee of this journal for the helpful comments received. Naturally, any errors that remain are mine alone.

\section{References}

Arestis, P. and P. Demetriades 1997: Financial development and economic growth: assessing the evidence. Economic Journal 107(442), 783-99.

Bacha, E.L. 1990: A three-gap model of foreign transfers and the GDP growth rate in developing countries. Journal of Development Economics 32, 279-96.
Bahmani-Oskooee, M. and Alse, J. 1993: Export growth and economic growth: an application of cointegration and error-correction modeling. The Journal of Developing Areas 27, 535-42.

Bahmani-Oskooee, M., Mohtadi, H. and Shabsigh, G. 1991: Exports, growth and causality in LDCs: a re-examination. Journal of Development Economics 36, 405-15. 
Balassa, B. 1978: Exports and economic growth: further evidence. Journal of Development Economics 5(2), 181-89.

Becker, G.S., Murphy, K.M. and Tamura, R.F. 1990: Human capital, fertility, and economic growth. Journal of Political Economy 98(2), S12-37.

Dickey, D.A., Bell, W.R. and Miller, R.B. 1986: Unit roots in time series models: tests and implications. The American Statistician 40, 12-26.

Doornik, J.A. and Hendry, D.F. 1997: Modelling dynamic systems using PcFiml 9.0 for Windows. London: International Thomson Business Press.

Feder, G. 1983: On exports and economic growth. Journal of Development Economics 12(1-2), 59-73.

Ghatak, S. and Price, S.W. 1997: Export composition and economic growth: cointegration and causality evidence for India. Review of World Economics 133(3), 538-53.

Granger, C.W.J. and Newbold, P. 1974: Spurious regressions in econometrics. Journal of Econometrics 2, 111-20.

Heller, P. and Porter, R. 1978: Exports and growth: an empirical reinvestigation. Journal of Development Economics 5(2), 191-93.

Hendry, D.F. 1995: Dynamic econometrics. Oxford: Oxford University Press.

Henriques, I. and Sadorsky, P. 1996: Export-led growth or growth-driven exports? The Canadian case. Canadian Journal of Economics 29(3), 540-55.

Johansen, S. 1988: Statistical analysis of cointegration vectors. Journal of Economic Dynamics and Control 12, 231-54.

Johansen, S. 1991: Estimation and hypothesis testing of cointegration vectors in Gaussian vector autoregressive models. Econometrica 59, 1551-80.

Jung, W.S. and Marshall, P.J. 1985: Exports, growth and causality in developing countries. Journal of Development Economics 18, 1-12.

Khan, M.S., Montiel, P.J. and Haque, N.U., editors 1991: Macroeconomic models for adjustment in developing countries. Washington DC: International Monetary Fund.

King, R.G. and Levine, R. 1993: Finance, entrepreneurship and growth. Journal of Monetary Economics 32, 1-30.

Levin, A. and Raut, L.K. 1997: Complementarities between exports and human capital in economic growth: evidence from the semiindustrialized countries. Economic Development and Cultural Change 46(1), 155-74.

Levine, R. and Renelt, D. 1992: A sensitivity analysis of cross-country growth regressions. American Economic Review 82(4), 942-63.

Lucas, R.E. 1988: On the mechanics of economic development. Journal of Monetary Economics 22(1), 3-42.

Maizels, A. 1968: Exports and economic growth in developing countries. London: Cambridge University Press.

Mallick, S.K. 1995: International trade and economic growth: an examination of interdependence using VARs with reference to India. Journal of Foreign Exchange and International Finance 8(4), 437-46.

Mallick, S.K. 2001: Dynamics of macroeconomic adjustment with growth: some simulation results. International Economic Journal 15(1), 115-39.

Mallick, S.K. and Kumar, T.K. 1995: Macroeconomic adjustment in India: policy and performance in the recent years. Journal of Indian School of Political Economy 7(1), 44-68.

Michaely, M. 1977: Exports and growth: an empirical investigation. Journal of Development Economics 4(1), 49-53.

Nelson, C.R. and Plosser, C.I. 1982: Trends and random walks in macroeconomic time series. Journal of Monetary Economics 10, 139-62.

Palley, T.I. 1996: Growth theory in a Keynesian mode: some Keynesian foundations for new endogenous growth theory. Journal of Post Keynesian Economics 19(1), 113-36.

Palley, T.I. 1997: Aggregate demand and endogenous growth: a generalized KeynesKaldor model of economic growth. Metroeconomica 48(2), 161-76.

Perron, P. 1988: Trends and random walks in macroeconomic time series: further evidence from a new approach. Journal of Economic Dynamics and Control 12, 297-332.

Phillips, P.C.B. 1986: Understanding spurious regressions in econometrics. Journal of Econometrics 33, 311-40.

Quah, D. 1993: Empirical cross-section dynamics in economic growth. European Economic Review $37,426-34$.

Ram, R. 1985: Exports and economic growth: some additional evidence. Economic Development and Cultural Change 33, 415-25. 
Rao, V.K.R.V. 1952: Investment, income and the multiplier in an underdeveloped economy. Indian Economic Review 1(1).

Rebelo, S. 1991: Long-run policy analysis and long-run growth. Journal of Political Economy 99(3), 500-21.

Reserve Bank of India (RBI) 1999: Annual Report 1998-99. Bombay: RBI.

Romer, P.M. 1986: Increasing returns and long run growth. Journal of Political Economy 94(5), 1002-37.

Romer, P.M. 1990: Endogenous technological change. Journal of Political Economy 98(2), S71-103.

Solow, R.M. 1956: A contribution to the theory of economic growth. Quarterly Journal of Economics 70, 65-94.
Taylor, L. 1991: Income distribution, inflation and growth. Cambridge MA: MIT Press.

Taylor, L. 1994: Gap models. Journal of Development Economics 45(1), 17-34.

Toda, H.Y. and Phillips, P.C.B. 1994: Vector autoregression and causality: a theoretical overview and simulation study. Econometric Reviews 13(2), 259-85.

Tyler, W.G. 1981: Growth and export expansion in developing countries: some empirical evidence. Journal of Development Economics 9(1), 121-30.

van Wijnbergen, S. 1983: Interest rate management in LDCs. Journal of Monetary Economics 12, 433-52. 